5 Trier JS, Phelps JC, Eidelman S, Rubin CE. Whipple's disease. Gastroenterology 1965; 48: 384-407.

6 Krauntz RF. Whipple's disease with cardiac and renal abnormalities. Arch Intern Med 1969; 123: 701-6.

7 Lie JT, Davis JS. Pancarditis in Whipple's disease: electron7 Lie JT, Davis JS. Pancarditis in Whipple's disease: electronAm f Clin Pathol 1976; 66: 22-30.

8 Enzinger FM, Helwig EB. Whipple's disease. A review of the literature and report of fifteen patients. Virchows Arch (A) 1963; 336: 238-69.

9 James TN, Haubrich WS. Bacterial arteritis in Whipple's disease. Circulation 1975; 52: 722-31.

10 Southern JF, Moscicki RA, Magro C, Dickersin GR, Fallon
JT, Bloch KJ. Lyphoedema, lymphocytic myocarditis, and sarcoidlike granulomatosis: manifestations of Whipple's disease $7 A M A$ 1989; 261: 1467-70.

11 McAllister HA, Fenoglio JJ. Cardiac involvement in Whipple's disease. Circulation 1975; 52: 152-6.

12 Rose AG. Mital stenosis in Whipple's disease. Thorax 1978; 33: $500-3$.

13 Fleming JL, Wiesner RH, Shorter RG. Whipple's disease: clinical, biochemical, and histopathological features and assessment of treatment in 29 patients. Mayo Clin Proc 1988; 63: 539-51.

14 Sossai P, DeBoni M, Cielo R. The heart and Whipple's disease. Int f Cardiol 1989; 23: 275-6.

\title{
Central pontine myelinolysis following orthotopic liver transplant: association with cyclosporine toxicity
}

Mustafa H Kabeer, Ronald S Filo, Martin L Milgrom, Mark D Pescovitz, Stephen B Leapman, Lawrence Lumeng, Rahul M Jindal

\begin{abstract}
Summary
Central pontine myelinolysis can occur after orthotopic liver transplantation leading to high mortality and serious morbidity. In our case, central pontine myelinolysis was associated with wide fluctuations in cyclosporine levels during an episode of hypocholesterolaemia, which may have precipitated central pontine myelinolysis.
\end{abstract}

Keywords: central pontine myelinolysis, liver transplantation, cyclosporine

\section{Introduction}

Central pontine myelinolysis is a distinctive lesion seen after a variety of conditions (box 1). ${ }^{1-3}$ With the widespread application of orthotopic liver transplantation, neurological complications such as central pontine myelinolysis has again come into focus. ${ }^{4}$

Since the introduction of cyclosporine and the new immunosuppressant FK506, neurological toxicity has been increasingly recognised as a complication of both therapies (box 2). Also reported are instances of akinetic mutism, severe dyskinesia and pseudo-bulbar

\begin{tabular}{|l|}
\hline Central pontine myelinolysis: \\
causes \\
\hline - rapid correction of sodium and osmolality in \\
patients who have underlying liver disease \\
- malnutrition \\
- alcoholism \\
- pneumonia \\
- lymphoma malignancies \\
- severe burns \\
\hline
\end{tabular}

palsies. ${ }^{7}$ It has been shown that cyclosporine neurotoxicity is specifically aggravated by low magnesium and low cholesterol levels. ${ }^{8}$

We report a case of central pontine myelinolysis after orthotopic liver transplantation in which high cyclosporine levels may have led to seizure activity, and central routine myelinolysis subsequently developed due to re-initiation of cyclosporine during an episode of hypocholesterolaemia.

\section{Case report}

A 50-year-old white man with end-stage liver disease secondary to cryptogenic cirrhosis was transplanted uneventfully with an ABOcompatible liver. During surgery there was no evidence of haemodynamic disturbances such as excessive blood loss or re-perfusion syndrome. Neurologic examination before transplantation was normal. His immunosuppressive protocol consisted of Imuran (iv $2 \mathrm{mg} / \mathrm{kg}$ ), methylprednisolone (iv $1 \mathrm{mg} / \mathrm{kg}$ ) and iv cyclosporine ( $2 \mathrm{mg} / \mathrm{kg}$ by continuous infusion) and switched to po medication when tolerated. He was extubated on the second day and was awake and neurologically stable, as were his other systems.

\begin{tabular}{|l|}
\hline Neurological complications of \\
cyclosporine toxicity \\
\hline - headache \\
- tremors \\
- convulsions \\
- coma \\
- quadria \\
- cerebral blindness \\
\hline
\end{tabular}

Box 2 


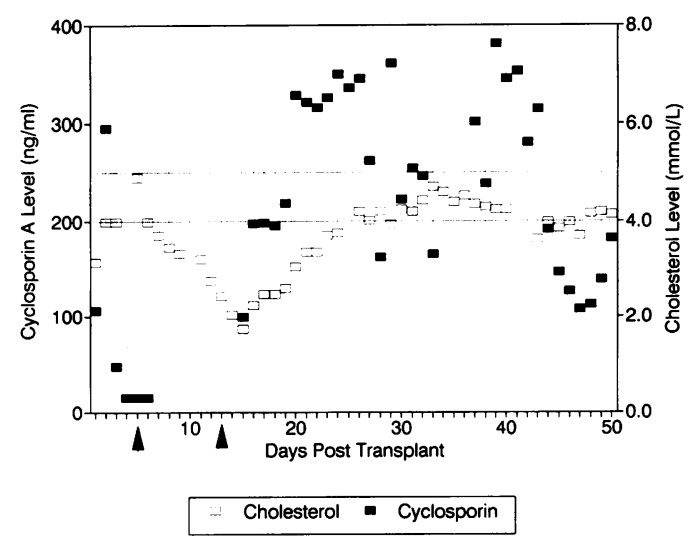

Figure 1 Cyclosporin A and serum cholesterol levels. The first arrow on the $x$ axis shows the day of seizure activity, the second arrow marks the onset of central pontine myelinolysis. the two horizontal lines on the $x$ axis mark the therapeutic levels of cyclosporine

On the fourth day, he developed tremors followed by typical grand mal seizures. The seizures were controlled by a combination of dilantin and phenobarbitone and by stopping cyclosporine. There was no evidence of a focal central nervous system (CNS) lesion, all cranial nerves were intact and reflexes were normal). During the time he was off cyclospoine, he continued to receive steroids and Imuran. On day 14 when intravenous cyclosporine was re-initiated, he developed global asphasia, bilateral facial nerve paralysis, quadriplegia, and loss of anal sphincter tone. It was noted at this point that cholesterol levels were low. Figure 1 shows cyclosporine (trough levels, the horizontal band on the $\mathrm{X}$ axis shows therapeutic levels) and serum cholesterol levels.

Computed tomography (CT) scan of the head on day 4 and repeated on day 14 , showed generalised atrophy with prominent ventricles but no evidence of central pontine myelinolysis. As we suspected central pontine myelinolysis, magnetic resonance imaging (MRI) of the head was obtained which showed abnormal signals on the saggital T2-weighted image in the thalamic and pontine areas (figure 2) and also on axial T1-weighted image (figure 3). These MRI findings were typical of central pontine myelinolysis. Lumbar puncture showed no evidence of infection.

He has made a slow recovery, being able to follow commands that are not physically taxing. MRI of the head at 1 and 6 months later (not shown) again showed evidence of central pontine myelinolysis. The cortical spinal tracts remained spared. There were gyriform and pial enhancements which were not present earlier, the significance of which is not clear.

\section{Discussion}

Central pontine myelinolysis is a serious complication after orthotopic liver transplantation, which results in high mortality, ${ }^{8}$ but some recover to a variable extent, both clinically, ${ }^{9}$ as shown in our case, and radiographically.$^{10}$ In

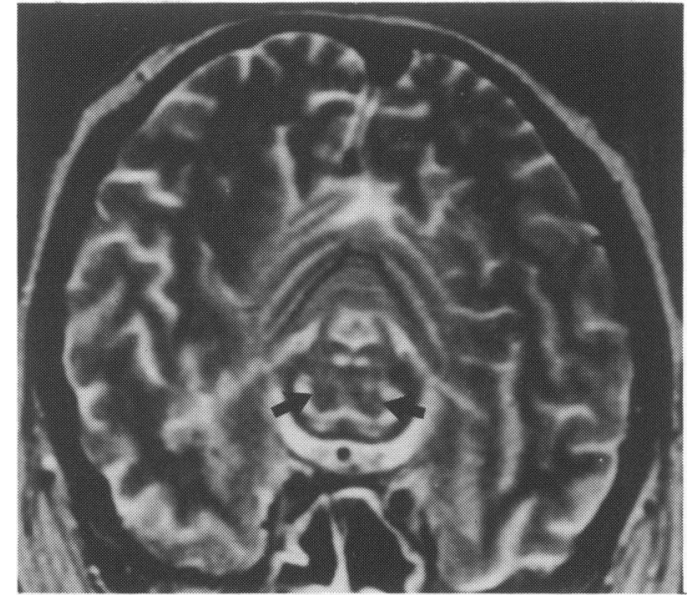

Figure 2 Sagittal T2-weighted MRI showing an area of increased signal intensity within the basis pontis

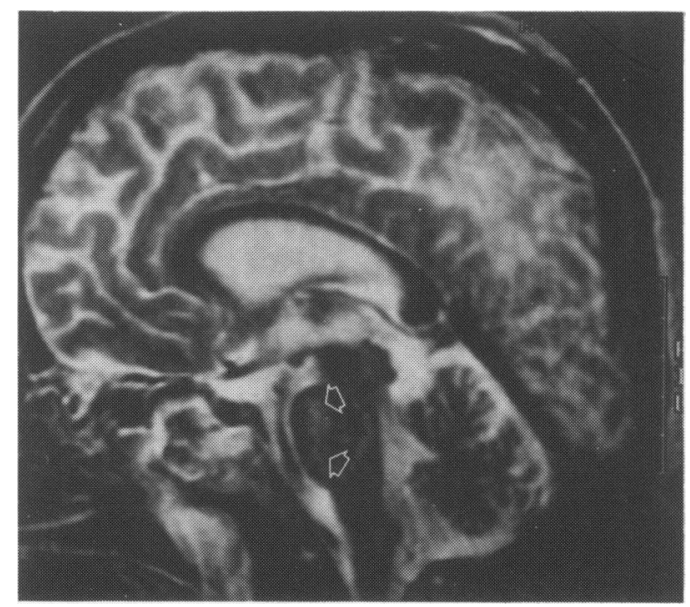

Figure 3 Axial T1-weighted image showing an area of pontine central myelinolysis and sparing of cortical spinal tracts

our case serum sodium and magnesium were within normal limits. Serum cholesterol was the only variable which went to subnormal levels at two weeks posttransplant. The first seizure (marked by arrow in figure 1) occurred when the cyclosporine level precipitously dropped from 300 to 20 (monoclonal method measuring the parent compound), followed by unusually rapid fluctuations of cyclosporine levels when this drug was reintroduced. More significant was the fact that cyclosporine was restarted on day 14 (marked by arrow in figure 1) during a period of hypocholesterolaemia. This combination of iv cyclosporine and low cholesterol may have aggravated neurological toxicity. Other authors have found similar association between serious neurological toxicity after liver transplantation and hypocholesterolaemia. ${ }^{8}$ The patient was not on any drugs known to increase cyclosporine levels.

Central pontine myelinolysis is probably the most devastating neurological complication which can follow orthotopic liver transplantation. Other neurological manifestations which 


\section{Learning points}

- central pontine myelinolysis may occur following liver transplantation

- cyclosporine neurotoxicity is aggravated by low magnesium and cholesterol levels

may be part of the central pontine myelinolysis syndrome include confusional state, psychosis, cortical blindness, focal paralysis, aphasia, ataxia, visual hallucinations, and seizures. ${ }^{11}$ The nature of the brain lesions seen on CT and MRI in central pontine myelinolysis is not clear. ${ }^{12,13}$ High cyclosporine levels in one series correlated with seizure activity, ${ }^{14}$ which may be a harbinger of central pontine myelinolysis, although this association has not been consistently demonstrated. In one autopsy series, ${ }^{15}$ CNS lesions that purportedly accounted for seizures and central pontine myelinolysis were found in 19 of 21 cases, however, these authors

1 Wszolek ZK, McComb RD, Pfeiffer RF, et al. Pontine and extrapontine myelinolysis following liver transplantation. Transplantation 1989; 48: 1006-12.

2 McKee AC, Winkelman MD, Banker BQ. Central pontine myelinolysis in severely burned patients: relationship to serum hyperosmolality. Neurology 1988; 38: 1211-7.

3 Estol CJ, Faris AA, Martinez AJ, et al. Central pontine myelinolysis after liver transplantation. Neurology 1989; 39: 493-8.

4 Boon AP Carey MP, Salmon MV Central pontine myelinolysis not associated with rapid correction of myelinolysis not associated with

5 Stein DP, Lederman RJ, Vogt DP, et al. Neurological complications following liver transplantation. Ann Neuro 1992; 31: 644-9.

6 Adams DH, Gunson B, Honigsberger L, et al. Neurological complications following liver transplantation. Lancet 1987 1: $949-51$

7 Bird GLA, Meadows J, Goka J, et al. Cyclosporinassociated akinetic mutism and extrapyramidal syndrome after liver transplantation. $f$ Neurol Neurosurg Psychiatry 1990; 53: $1068-71$

8 Boon AP, Adams DH, Buckel JAC, et al. Neuropathologica findings in autopsies after liver transplantation. Transplantation Proc 1991; 23: 1471-2.

9 Pfister HW, Einhaupl KM, Brandt T. Mild central pontine myelinolysis: a frequently undetected syndrome. Eur Arch Psychiatry Neurol Sci 1985; 235: 134-9. did not consider cyclosporine to be a significant factor.

In our case neurological symptoms may have been precipitated by rapid fluctuations in cyclosporine levels in combination with low cholesterol. Another explanation for central pontine myelinolysis could be an idiosyncratic reaction of cyclosporine as this drug readily crosses the blood-brain barrier ${ }^{16}$ and could be an idiosyncratic response.

Care should also be taken to correct cholesterol abnormalities. CT scan may fail to detect the lesions associated with central pontine myelinolysis. MRI ${ }^{17}$ has been found to be more sensitive and specific, particularly in the early period, as shown by our case.

In summary, central pontine myelinolysis occurred in our patient despite careful fluid-electrolyte management and uneventful surgery and was probably related to intravenous cyclosporine. Low serum cholesterol may also have contributed to central pontine myelinolysis.

10 Ragland RL, Duffis AW, Gendelman S, et al. Centra pontine myelinolysis with clinical recovery: $M R$ documentation. f Comput Assist Tomogr 1989; 13: 316-8.

11 DeGroen PC, Aksamit AJ, Rakela J, et al. Central nervous system toxicity after liver transplantation: the role of cyclosporine and cholesterol. $N$ Engl 7 Med 1987; 317: 861-6.

12 Truwit CL, Denaro CP, Lake JR, et al MR imaging of reversible cyclosporin A-induced neurotoxicity $A m$ of Neuroradiol 1991; 12: 651-9.

13 Truwit CL, Denaro CP, Lake JR, et al. MR imaging of reversible cyclosporin A-induced neurotoxicity. Am $\mathcal{F}$ reversible cyclosporin A-in

14 Appelton RE, Farrell K, Teal P, et al. Complex partial status epilepticus associated with cyclosporin A therapy. $\mathcal{F}$ Neuro Neurosurg Psychiatry 1989; 52: 1068-71.

15 Estol CJ, Lopez O, Brenner RP, et al. Seizures after liver transplantation: a clinicopathologic study. Neurology 1989 39: 1297-301.

16 Azoulay D, Lemoine A, Dennison A, et al. Incidence of adverse reactions to cyclosporine after liver transplantation is predicted by first blood level. Hepatology 1993; 18: 1123-6.

17 Bronster DJ, Emre S, Sheiner P, Miller CM, Schwartz ME. Neurological complications of orthotopic liver transplantation. Mt Sinai f Med 1994; 61: 63-9. 